\title{
A year (and more) of sociodrama online: the Covid era 2020/2021
}

\author{
Diane Adderley
}

Accepted: 6 May 2021 / Published online: 18 June 2021

(C) Springer Fachmedien Wiesbaden GmbH, ein Teil von Springer Nature 2022

\begin{abstract}
This article of the Zeitschrift für Psychodrama und Soziometrie (ZPS) is about Sociodrama online in the Covid Era 2020/2021. In 2020/2021, there have been a wide range of experiential sociodrama events offered online, often varying widely in form and purpose between practitioners from the different 'schools' of thought about what is sociodrama and how to do it. This account is avowedly subjective, written from the perspective of Diane Adderley, UK-based Senior Sociodrama Trainer, during the period to date of the Covid-19 pandemic. It details the development of iSCAN, an initially mainly UK-based network of sociodramatists, which now includes in its core group practitioners from Germany, USA, Australia (via Beijing) and Romania. Other international initiatives are also briefly introduced. The role of sociodrama in today's changing world together with the opportunities and pitfalls of the Zoom experience are explored, together with some brief reference to the demarcation between psychodrama and sociodrama and the definitions of the form found to be most useful to the writer.
\end{abstract}

Keywords Sociodrama - Zoom · iSCAN · Connection · Social roles · Training · Director · Warm-up · Breakout rooms

\section{In the beginning ...}

In early March 2020, Dr. Ron Wiener, Senior Sociodrama Trainer with the British Psychodrama Association (BPA), and my original trainer in the method, invited a small group of colleagues, ex-students and graduates of the UK's previous school

Diane Adderley $(\bowtie)$

British Psychodrama Association (BPA), Manchester, UK

E-Mail: diadderley@gmail.com; info@sociodrama.co.uk

UK Council for Psychotherapy (UKCP), America House, 2 America Square, London, UK 
of sociodrama, MPV/SAM, to join him in an online peer group meeting. The purpose was to consider and practice together how we might produce sociodrama and action methods via Zoom video conferencing. It was also to provide a connecting matrix for the participants as we entered our first lockdown on March 22nd, and Covid19's onslaught on the UK population began its rampage. As I write, in April 2021, the UK is tentatively beginning its exodus from its third period of lockdown, as the vaccination programme gathers pace, and serious illness and mortality figures decline. I am all too painfully aware that many places in the world have yet to have the opportunity to begin vaccinating their populations to any significant degree or even at all.

\section{Why sociodrama?}

Sociodrama definitions abound around the world and this chapter is too short a place to go into them all. To cite but a few: sociodrama is ...

... a deep action method dealing with inter-group relations and collective ideologies ... the true subject of a sociodrama is the group ... (which) is already organised by the social and cultural roles (J.L. Moreno 1993, p. 59)

We are simply assisting a group to tell a story (Ron Wiener-verbal communication)

Sociodrama is a learning method that creates deep understanding of the social systems and social forces that shape us individually and collectively (Rollo Browne 2011, p. 12)

... an experiential group-as-a-whole procedure for social exploration and intergroup conflict transformation (Peter Kellerman 1998, p. 181)

... a group action method in which participants act out agreed upon social situations spontaneously ... sociodrama concerns itself with those aspects of roles we share with others (Patricia Sternberg and Antonina Garcia 2000, p. 4)

Sternberg \& Garcia and others (for example, the Spanish practitioner Pablo Alvarez Valcarce) place emphasis on the necessity for the dramas to be exploring only hypothetical situations. However, some practitioners nowadays (including myself) sometimes use real-life situations as the starters for what is termed Protagonist-Centred Sociodrama, exploring how such stories are upheld, embedded, and maintained in our cultures by the systems which sustain them (see Wiener 2011, pp. 29-31). There are also many practitioners in South America who lead large, out-on-thestreets sociodramas and much writing which has yet to be translated into other languages - as I do not speak Spanish or Portuguese, I cannot comment on these.

My own preference and training lean towards the simpler definitions of Wiener and Browne, which encapsulate the creative-spontaneous (a group tells a story) with the pragmatics of learning and understanding (the social-educational learning component). The difference for me between sociodrama and psychodrama is in purpose and the broad-based methodology, though many 'techniques' are the same in both forms. In simple terms, in sociodrama, we explore systems-the wider horizontal view, in order to see the bigger picture. In psychodrama, we look at 
the individual psyche-deep-diving into a person's history and culture to achieve insight and hopefully personal change (this may also, of course, involve systemic exploration of the social/cultural atom of the individual at different stages of life).

Sociodrama seems to me to be a more appropriate and, from my limited experience, more effective way of working with groups online than psychodrama. In these times of massive change in the world together with the necessity for massive environmental change globally in the immediate future, to be able to develop worldwide conversations seems to be a tremendous advantage. And the internet with video conferencing gives us the means to do this.

\section{Back to March 2020}

I had never previously considered, let alone actually experienced, a sociodrama done via video conference and initially I felt excited and grateful for this connection with my peers, but doubtful that sociodrama could work as an online modality. In the beginning, the group consisted of Ron Wiener and myself, Valerie Monti Holland (Trainer in Sociodrama), Irina Stefanescu from Romania (coach, psychodramatist and sociodramatist, graduate of MPV/SAM), Phil Helm (UK psychodramatist) and Gunjan Dixit, a keen member of Ron's regular improvisation groups and a student of Applied Theatre, locked down in her small Hall of Residence room at Leeds University. She was delighted to be included and to have this small window onto the outside world which Zoom provided. Here already was a purpose for what we were doing: connection with and for other human beings in the only way it was available to us.

Throughout 2020 and now well on into 2021, we have continued to meet for two hours every week, almost without fail. This regular group has become, at least for me, a lifeline to the world we used to know, running workshops, teaching, facilitating, travelling to international conferences and events, meeting colleagues in real life, even as (in physical reality) I travel from my living room to my upstairs back bedroom office where Zoom awaits.

Originally, we saw our little group as a continuation and resurgence of SCAN (Sociodrama and Creative Action Network), a peer learning group which had continued to meet occasionally after our sociodrama school had closed in 2012. Once we had the experience of the international nature of sociodrama online, we, rather cheekily perhaps, renamed ourselves iSCAN (International Sociodrama and Creative Action Network), with a nod towards the IT world we were now inhabiting (and also, perhaps to the iMacs, iPads and iPhones many of us were relying upon).

People have since come and gone, others have popped in for the occasional meeting, we have struggled with the many complexities of the online environment, have gathered other members into the core group from as far afield as the USA (Sheila Katzman, Applied Theatre practitioner, broadcaster and journalist, sociodramatist), China (Tom Schwarz, an Australian psychodramatist and facilitator based in Beijing) and Jörg Jelden and Valentin Heyde (both organisational consultants and sociodramatists, who live and work in Germany). We have become both a team who set up, advertise and run online sociodrama events and a peer learning set, at which 
we review workshops that members have run in other places, plan future events in the wider world, check in with each other, discuss aspects of sociodrama, share ideas from other online events we have attended, of which there are now legion, and generally keep our sociodramatic connection not only going but positively blooming.

\section{Early workshops-Spring/Summer 2020}

To step back again in time to May 2020, the original group took the plunge and offered a series of free workshops to members of the BPA (British Psychodrama Association) on various aspects of the global story of the pandemic. The first one was called "Sociodramatists in a Changing World", directed by Ron Wiener with able technical support from Irina Stefanescu. We were referencing our book, Sociodrama in a Changing World, published in 2011 (Wiener et al. 2011; www.lulu. com, available also on Amazon). I can't remember much about that one now, except that it worked-we could connect with a large-ish group over Zoom and do useful sociodramatic explorations.

These free sessions were attended by people from much further afield than just the UK and we started to get our first taste of the global conversation that sociodrama on Zoom offers as a possibility. We also started to learn how to manage much larger numbers online than we had been used to in workshops with physically-present participants. How to decide how many people to accept? What could the directors manage? How does the director keep connection with the group, especially when numbers dictate that there may be two or more screens of 25 participants on each? There were many little difficulties, of course - the cry of "I can't find the link — send it again"; internet 'unstable' messages; people being refused entry from the waiting room as their Zoom ID had not been recognised; the intermittent 'freeze' of either oneself or someone else; the necessity to leave the meeting and re-enter when audio failed; the complexities of breakout rooms and people being left in solitary isolation somewhere in the virtual world. And so many more! Of course, we wanted to look good, competent, appearing to know what we were doing in this new world, assisting in the global conversation and not creating more stressors for those who joined us. It was also, perhaps, a way of containing our own personal anxieties about life going forward.

Different members of our group took on the lead facilitator role in these early workshops, with others offering technical and breakout room support. I, with some trepidation, directed my first sociodrama online in this series, at a time when it looked as if the worst onslaught of the virus might be diminishing. I called the session Blinking into the Light, having dreamed an image of being in a cave and looking out to the world beyond with a mixture of feelings: longing to get out of the stifling, perhaps anxious space of both the internal and external 'cave' of our lockdown existence. How safe would it be to emerge? How might we feel about engaging with the world of real people again? How would we deal with the grief and the losses we had experienced? A year later, these questions carry an even deeper significance as the pandemic appears to be so much worse now and, despite the 
advent of successful vaccines, any return to so-called 'normality' still seems a long way off.

Irina Stefanescu was my technical support on Blinking into the Light, managing the Breakout Rooms, Whiteboard etc. Irina is very very good at Zoom tech. In these early days we used to open the Zoom meeting room at least 30 min early for those who needed technical help. At this time, and for some months, many did. Now this is less necessary-most people have learned how to switch on and off their camera and microphone, find the annotate bar on the Whiteboard, rename themselves with the social role they wish to speak from, how to 'Hide non-video participants' (so helpful if you just want to see the active role-players onscreen), how to put messages into the Chat.

Working in the corporate rather than the therapeutic world, Irina is also highly experienced at (and generously willing to spend her time) putting together relevant presentations-PowerPoint, YouTube videos, free online images-all made their appearance in the warm-up phases of our sessions. In this one, we had images showing the view from inside a cave, looking outwards, children outside the cave, blinking into the sunlight. I invited the group to double the children, what might they be thinking and feeling as they gazed outward. This warm-up took us on into small group work in Breakout Rooms, exploring thoughts and feelings, telling stories and choosing and developing the initial social roles that would then be brought back into the plenary session for a fuller sociodrama enactment.

At that time, people in England were allowed to meet up outdoors with no more than five others. In Scotland, the maximum 'association' allowed was eight people in total. Here was the setting for the sociodrama enactment, evoked in the imagination by a picture of a rustic picnic table with benches to seat eight people, in an inviting warm and sunny outdoor setting. I invited eight participants to enter the 'stage' (by switching their video cameras on), renaming themselves as the social role they had chosen to portray, and asked the group to manage the number themselves, as we were having to do in life, so if a ninth person in a role came onto the screen someone would have to leave.

Sociodramatically, we found it necessary not only to do Zoom technical training before moving into action, but also to explain briefly to participants how we understood the term 'social role', a crucial concept when one is trying to look at the wider social systems in which we live, not primarily the individual's system which is required more in a psychodrama group. One useful and basic way to think about this is to pick an action role-social worker, doctor, police officer, government official, journalist, trade unionist, parent, student, immigrant-each one of which will, in the first instance, be considered to have certain characteristics in common with most other inhabitants of the role. A descriptive word or phrase can then be added to the role to delineate the particular way in which the role is played-angry social worker, exhausted doctor, inexperienced police officer, manipulative government official, left-wing journalist, despairing trade unionist etc. Through role interviewing, either by the director or group members, we can then deepen the role-taking, so the enactment can move through to deeper levels of warm-up. Taking the example of a Politician, the levels may be thought of as: 
- Level 1 Stereotype e.g. the 'cartoon' version of a Politician

- Level 2 Typical-how might a 'typical' Politician behave

- Level 3 You as ... i.e. how might you be if you were a Politician

- Level 4 You here and now in the group - this involves your current links in the actual group you are participating in, subgroups and characteristic behaviours, how 'political' do you have to be here to be heard/feel safe (this level is perhaps less commonly activated in a one-off group)

- Level 5 You in your own life ... e.g. your own thoughts, feelings and behaviours in your own internal role of Politician, perhaps in the present or past family or a work team.

The level of warm-up may be described as "the extent to which participants bring their personal selves into an enactment" (Browne, training handout, 2006). Online, we have generally seen role-taking in sociodrama deepening to Level 3 in plenary enactments, though in the smaller groups of the Zoom Breakout Rooms, sometimes that more intimate environment encourages development further along the continuum.

There are, of course, other ways of thinking about roles, given that, certainly in a psychodrama, anything can be a role-as long as the participant can 'become' the role, animating it with thoughts and feelings, giving it meaning: in one drama, a participant named themselves "A birthday present"-a role whose meaning had emerged in a breakout room story as a surprisingly life-affirming, joy-inducing, funproducing gift which had totally transformed the lockdown birthday of the receiver.

Perhaps a more easily understood description of levels of role playing was developed by my colleagues Jörg Jelden and Ron Wiener. In an email to our group (dated 1/2/21) Jörg describes their adapted version, which he had found more useful in his corporate work:

- Stereotypical: what images, metaphors, ... do you have of this role?

- Knowledge: what actual knowledge do you have about this role?

- Experience: What experience do you have with this role?

- Similar Situations: What similar situations have you experienced that might inform you for this role?

- Ideal role: How would you ideally fill this role?

And, of course, we also have values (love or courage), objects, natural elements etc. that can be developed into roles. Tom Schwarz, another member of our iSCAN core group, likes to ask what beneficial gifts and hindrances (yin and yang) might this role bring to you in your own life (Level 5) and he sees Browne's 'laddering' of role development as a way of "working from the periphery to the core" (email $2 / 2 / 21$ to the iSCAN practice group).

We also, of course, discovered not only how tiring workshops on Zoom can be, for both leaders and participants, but also how everything seems to take longer, so a two-hour workshop struggles to fit in all the component parts and often a thorough sharing at the end becomes very squeezed. To do an adequate warm-up (to self, other and purpose) takes considerable time, and without it the resulting enactment will struggle to deepen beyond the superficial. Our iSCAN group has now largely 
settled on a preference for three-hour workshops, with a break, as the length of time needed to be able to fulfil, not only the warm-up/enactment/sharing trio of the normal Morenian structure, but also all the other time-consuming aspects of the online environment, such as movement in and out of breakout rooms, on and off screen, remembering to mute or unmute one's microphone etc., which all set the clock ticking.

\section{Migration Matters Festival, June 2020}

This festival was created originally by Valerie Monti Holland's son, Sam. It had been funded by the Arts Council of England (ACE) for some years, who were open to the idea of it moving online in 2020 .

In 2019, Ron Wiener had run a 'live' sociodrama event in Sheffield at the festival, on the theme of The Wall, looking at both the actual and the metaphorical concept of the wall as a potent image for the situation of migrants everywhere, across time and space. (In 2020, I saw Nina Garcia use Robert Frost's poem 'The Wall' as a warm-up to sociodrama in the online setting.) In an actual theatre space, and assisted by Valerie, Ron had collected many empty cardboard boxes for participants to build physical barriers, which came to have multiple meanings as the drama emerged. Unsurprisingly, the majority of the participants, many of whom were both immigrants and new to the sociodrama method, were somewhat resistant to taking on the roles of the wall builders - the boundary holders, immigration officials, the Trumps of the world, racist bigots, populist politicians - preferring, understandably, to demolish the cardboard walls created.

A year later, in mid-June 2020, our iSCAN group was invited to run a session in this online version of the Migration Matters Festival, which would be attended both by on-screen participants and by those watching on a livestream via Vimeo and FaceBook. I was keen to build on my previous experience of directing online so volunteered to take on the role with technical and breakout room support from the team. We have increasingly found that it can be very useful to have an iSCAN team member in each breakout room group wherever possible, to help focus the small groups. Of course, every time you create a small group that is new to each other in a breakout room, you are creating a new group, that needs time to do all the things new groups need to do before much can be done creatively: introduce themselves, feel out the small group dynamics (how will we work together, who will take a leadership role, who will wait for others to take the initiative), develop a working relationship re the task they have been set, learn to trust their own spontaneity and creativity in this new setting. One of the most common issues we've heard over and over on Zoom is people feeling they don't have enough time in these small groups, that they are just getting going together when they are drawn back into the main plenary session by the time clock.

This time, our session title, created by Valerie, was Getting out of Quicksand: Stuckness and Self-Determination - a theme which could equally apply to migration questions as to pandemic experiences. We found a short video cartoon on YouTube of someone escaping quicksand and showed this as an initial warm-up. Pictures fol- 
lowed illustrating various kinds of stuckness and self-determination and participants were invited to write or draw their responses on the Whiteboard or in the Chat. Again, the device of presentation via Sharescreen followed by response generation was used as a warm-up to breakout room small group work and as a means of generating social roles for the plenary enactment to follow. On this occasion, the participants' small group task was to consider the following:

What does quicksand represent for you, what keeps us stuck, what helps us to be self-determining as we move into the future? Who are the people, organisations, countries, social institutions that have a say in this?

While the team were beavering away with their small groups, I stayed on the plenary screen and addressed the invisible participants on the livestream, giving some introduction to sociodrama and inviting questions or comments on what they had seen so far, which could be fed through technical support and typed into the Chat. This was a strange experience, particularly as I did not know how many people were accessing the livestream and interaction was slow in coming. The connection with the livestream audience felt much more tenuous than with the onscreen participants. As this is the only occasion on which I have directed a sociodrama event which is being livestreamed, I'm unsure at this time as to whether or not it's a useful addition to the techniques of online sociodrama.

Bringing the small groups back, I invited people to rename themselves in their chosen social role and come onto the screen to begin the enactment. This time we evoked the more relevant setting of a public meeting, showing pictures of several such events to further heighten the warm-up. We also wrote on the Whiteboard the roles people had prepared. Once the enactment begins, one of the director's key roles is to start to link up the roles that are offered and to encourage creation of roles that are needed but not yet on stage. Who does the Passionate, Exhausted Head Teacher need to speak to? Who could help the Overwhelmed Mother? How can the Desperate Freelance Artist find a voice? How can the Embattled Politician and the Impatient Grassroots Activist hear and understand the other's perspective?

After final statements from role and some brief sharing, we finished with inviting participants to listen to a story, perfectly illustrating our theme, told to us and then recorded especially for the session by our iSCAN colleague, Sheila Katzman:

\section{The story of the turtles}

In parts of the world where turtles are caught for food, hunters catch the animals by turning them over on their backs, using long sticks, when they come out of the sea and onto the sand to lay their eggs. On their backs, the turtles are helpless. However, they can defend themselves, before being turned over, by very quickly using their small but strong legs to scoop up and throw sand into their attackers' eyes to blind them, enabling the creatures to return to the sea.

This workshop was, I think, a successful experiment, which still exists as a recording on YouTube at: www.migrationmattersfestival.co.uk/2020/ionahine-cp2ra. 
As it is three hours long, I'd recommend, if you're interested, dipping into it to see how we were delivering sociodrama online at that time. It is also available on the iSCAN website, www.sociodrama.org.uk.

\section{7th International Sociodrama Conference, June 2020}

These conferences had been started initially by Portuguese psycho- and socio-dramatist Manuela Maciel, who is still steering the ship, now with a crew of international Morenian practitioners. 2020's conference had been planned as a live event in Portugal but of course the realities of the world had changed. Manuela and her team turned it into a Zoom conference. The four online presenters (Manuela, Monica Zuretti, Nina Garcia and Ron Wiener) each ran four workshops plus two panel discussions over five days, heroically exhausting themselves in the process of varying their workshop times so that people from around the world could have the opportunity to participate.

The iSCAN team took turns to support Ron in providing his workshops, each one different and developing on the previous one (though they were attended by a varying group each time). One of the things I most admire about Ron's creative spontaneity is his sense of anathema towards repeating what he's done before, so doing the same workshop four times would just not have worked for him! Each had to build on the lessons and outcomes of the previous one, so we would debrief together after each workshop so he could plan for the next. He constantly varied the sociodramatic question ("How can we ...") to reflect the unfolding of the group conversation and changed the structural format to gain more engagement and deeper role-taking.

Seeing and participating in the work of four international sociodramatists, each with their own developing 'take' on working online was invaluable to me. This was where I first encountered the role of 'Emotional Supporter', considered ethically essential by some of the presenters-a designated person available to support anyone who needed it in a breakout room, rather than have a distressed participant switch off their camera and leave the session, returning unsupported to their own physical reality outside the Zoom space. This role seems to have become a staple of many online sessions I have attended in recent months, though I have not yet seen it utilised.

\section{Other initiatives and experiences}

\subsection{TELE'Drama}

Over the course of the summer 2020 months, we also attended many other online initiatives such as Daniela Simmons TELE'Drama programmes (www.teledrama. org). Daniela has been working in the online environment for some years and is highly proficient at all the 'tech stuff', as well as being a fine psychodramatist in her own right. She hosts online psychodramas, sociodramas and socio-psychodramas as 
well as Playback Theatre events, Bibliodrama and many others with action methods practitioners from around the world-well worth investigating.

\subsection{FEPTO}

The Federation of European Psychodrama Training Organisations, responding to the needs of its many different schools for training in online working, set up a number of workshops with a Russian group led by Viktor Semenov, who had also been working online and developing his own team over a number of years. I attended these workshops and was particularly impressed with a sociodrama model he called Cultural-Historical Sociodrama. Viktor introduced this by warming up the group to the many epidemics there have been throughout history all over the globe. In breakout rooms, we brought to mind the different epidemics we were aware of from our own area of the world and started to create social roles through which we could explore the 'cultural-historical' stories that emerged. Back in plenary, Viktor invited a small number to come onto the Zoom stage in the roles we had begun to inhabit.

A character emerged in me, through the process of being interviewed in role, of a WWII soldier, an amputee, trying to find his family in the blitzed ruins of London and then trying to get out of London to find his brother, a patient in quarantine in a tuberculosis sanatorium. I was amazed by how emotional I felt creating and developing this character in that tiny Zoom window. I realised over the ensuing days that this very powerful role had come into my mind unbidden from three different sources:

- An apocryphal story, told in my own family, of a soldier who died in WW1, my grandfather's brother I think, who was said to have appeared at the back window of my grandparents' house on the day he died in the trenches of Europe;

- I was also remembering that the so-called 'iron lung' of the TB sanatoria was the precursor to today's ventilator, so desperately needed in these C-19 times;

- Lastly, I have a dear friend who is on immuno-suppressant drugs to support her transplanted kidney and who had, in recovery from the original surgery, developed latent TB which nearly killed her, as a result of her compromised immune system.

Extraordinary the workings of the unconscious mind when given the permission and opportunity to move from spontaneity to creative expression! Even on Zoom!!! One of the many things we have focused on in our iSCAN group has been the necessity for effective warm-up and the awareness that it does take longer when we do not have the actual physical presence of each other to generate our energy, spontaneity and creativity for the work. It can certainly happen, and in a very deep and powerful way, but it does take time and preparation.

\subsection{Performers2 (https://www.facebook.com/sociodramanetwork)}

Valerie Monti Holland, Irina Stefanescu and I are heavily involved in this threeyear, cross-European project which has Erasmus funding, to develop knowledge, training and literature on sociodrama in Europe, particularly in the field of working with marginalised youth. Spearheaded by the Hungarian Psychodrama Association 
and also involving many practitioners from Portugal, Sweden, Serbia and the UK, as well as a number of FEPTO representatives, we too have also had to move online in the last year, rather than meet in each other's countries. As this is a major project, with many project goals, this has been hard to continue. To co-ordinate many online meetings each month for the various international working groups, rather than meeting in-person for four-day block events abroad, has been a major undertaking as we have all been trying to manage everything that Covid has required of us in our own lives, as well as to find the windows of time when we can all meet up - no easy feat. It is happening, though, as we direct sociodramas with each other online, showing how, from our different cultures, we practise the method in our own contexts. We are developing a book, writing accounts of field work we do in our own countries, managing a website, learning from each other and developing a training framework for FEPTO's psychodrama schools with the purpose of incorporating sociodrama training more into 'mainstream' psychodrama training. We also meet up periodically online in a 'Sociodrama Café' to discuss, try out action methods, keep our international peer connections going, which are proving so very valuable to us all.

\subsection{The Peoples' Scenes (https://www.facebook.com/Escenas-de-los-Pueblos)}

Another online initiative is Monica Zuretti's Peoples' Scenes project. In South America, large scale public sociodramas have long been a feature of working Morenians there. Monica, from Argentina, conceived with colleagues the idea of sociodramas happening simultaneously all over the world, on the same day and, wherever possible, at the same time, in different languages, led by local facilitators, to develop the current global conversation about how we want the world to be when we come out of the pandemic.

The first event (sub-titled "What can I do for myself/my family/my community/my country/the world") happened in September 2020 and I attended one of the sessions led by Daniela Simmons and Andrea Wilches, from Argentina. I then co-ordinated and led iSCAN's offering in the December 2020 event, Caring in the Pandemic, in which I combined a kind of very simple Playback Theatre, the enactment of real stories of 'caring' and what that might mean, as the warm-up in breakout rooms to the subsequent sociodrama enactment on the main 'stage'. This proved very successful as a way to invoke social roles who then entered the plenary with great energy to encounter each other. It is intended to hold Peoples' Scenes events bimonthly. An offshoot of this project has been a fundraiser sociodrama, for those whose lives and homes were destroyed in two earthquakes last year in Serbia and Croatia. Again, this has led to calls for further fundraisers for other disaster areas around the world. None of this would have happened had we been in our 'local' inperson situations. Ironic, isn't it? 


\section{Current and future developments}

iSCAN is now developing a track record in running reputable online workshops, both for training in the methods and also on particular themes. In addition to variations on the pandemic theme, Valerie Monti-Holland and Jörg Jelden delivered a fine workshop on climate issues last Autumn. We have worked with Marie Pascale Gafinen (www.gafinen.com), who practises Generative Scribing, spontaneously creating colourful visual representations of the workshops we are running in the moment, as they are happening (Fig. 1).

We have run both short and weekend training events in using Zoom for group workers and have started a bi-monthly ALS (Action Learning Set), part facilitated, part peer-led for those who want a little bit of training and a lot of practice! We offer sociodrama supervision. We have also just started a 6-weekly drop-in group, peerled by the wider iSCAN membership (it costs just $£ 20$ a year to join iSCAN—go to www.sociodrama.co.uk for further information).

In March/April 2021, the group ran a four-session introductory training course in sociodrama and action methods, each session led by two of our core group and supported by other members of the team. There were sessions on issue-based, groupcentred and protagonist-centred sociodramas as well as some basic action methods training. We chose to offer a 'pay-as-you-can' policy, to financially enable as wide a participant group as possible and fixed our workshop times to accommodate participants from as wide a geographical area as we can, though we can't quite manage both west coast USA and China in one sitting at times that are amenable to human sleep-wake cycles. We are very keen to develop more workshops on the huge themes of our world, particularly climate questions and equality/diversity issues, not only

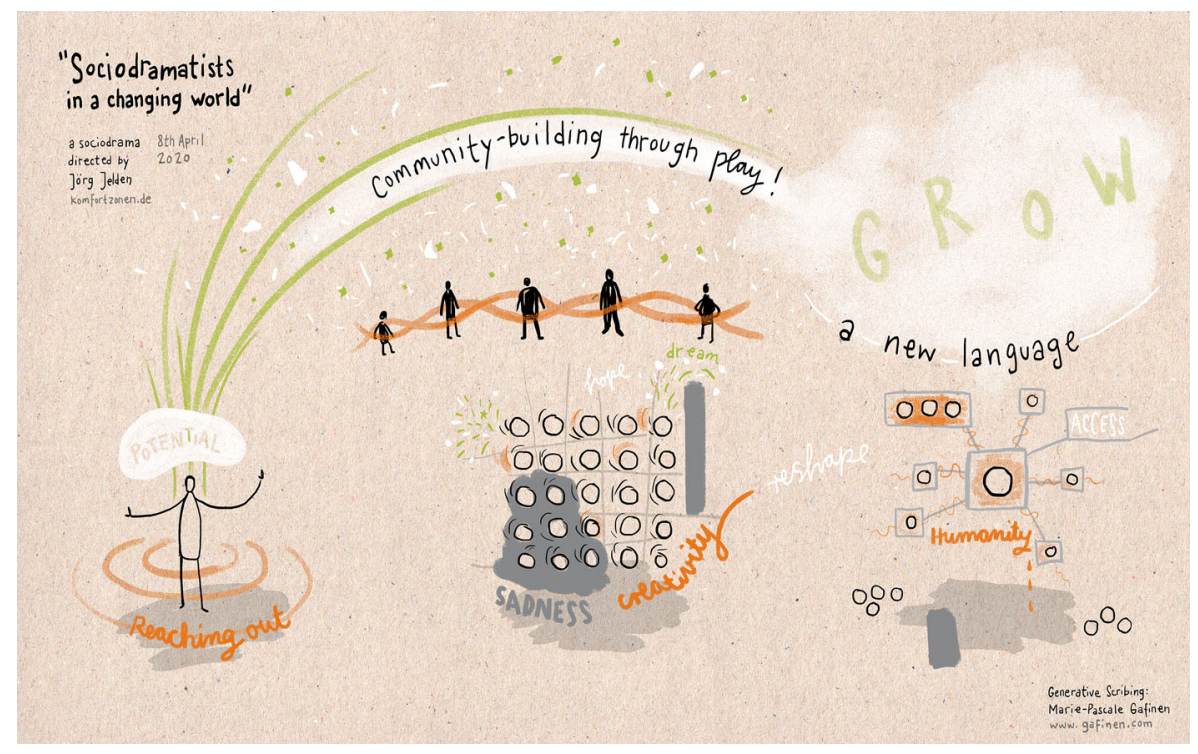

Fig. 1 Generative Scribing illustration by Marie Pascale Gafinen, from a sociodrama on 8th April 2020 
the pandemic, as our contribution to the global conversation on what changes the human race wants, needs, hopes or fears for our world, when we finally emerge from the Coronavirus cave.

\section{Opportunities and pitfalls}

At this point in time, I find it hard to make much of an evaluative comparison between online work and in-person, face-to-face connection. I need to get back to my consulting room or group training space to 'feel' the physical presence of 'the other' and notice what difference it makes. The technology enables the global nature of the conversations, but meeting others in 2-inch oblong boxes, in larger numbers than in-presence groups is draining, time-consuming, eye-straining, and physically (sitting) exhausting. It takes much longer to get participants organised into small groups (the ubiquitous breakout rooms) and out again. As the director, you miss so much of the 'buzz' of small groups all together in one actual physical space. I miss the physical transfer of energy from body to body. And yet, it has been all we have ...

In this extraordinary time, Zoom has given sociodrama the opportunity to play a much wider role and potentially be of much greater significance in the international arena of action exploration of our world. With no certain knowledge of when we will be able to meet as live in-presence groups again, I personally am so very grateful that there is this explosion of online activity, and excited to contribute where I can. Indeed, though it will be lovely to see actual people again when the time comes, I am mostly relieved to be able to work from home, spending no time having to walk down endless airport corridors and feeling guilty about my carbon footprint to work with colleagues abroad.

I am primarily, though, grateful to the sociodrama friends, colleagues and participants from all the above contexts, who have helped me enormously keep my sense of positivity, creative usefulness and meaning, at this time when isolation can be such a demoralising force. I can honestly say that sociodrama really has changed my world for the better in this past year (Fig. 2).

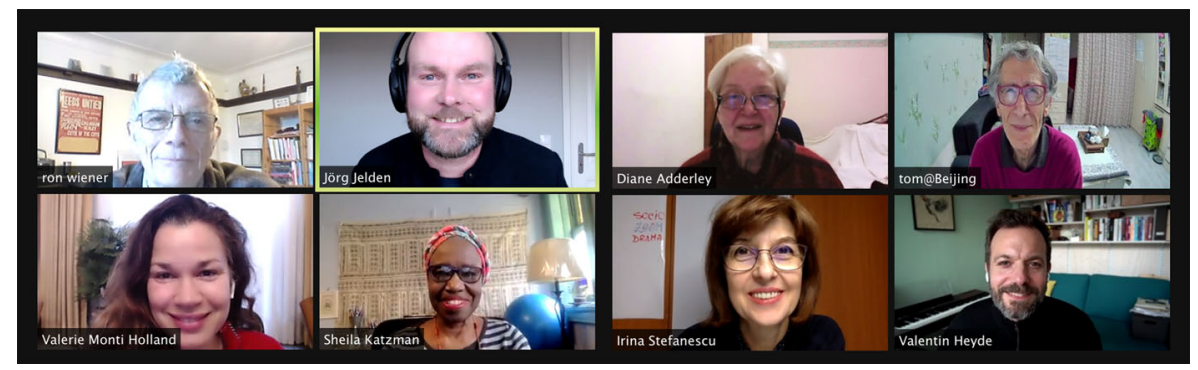

Fig. 2 iSCAN core group members in April 2021 


\section{References}

\section{Cited Literature}

Browne, R (2006). Understanding Levels of Warm Up in Sociodrama, Sociodrama Training Handout, Psychodrama Australia, Sydney Campus

Browne, R. (2011). Sociodrama with a marketing team. In R. Wiener, D. Adderley \& K. Kirk (Eds.), Sociodrama in a changing world (p. 12). www.lulu.com.

Kellerman, P. (1998). Sociodrama, group analysis. Vol. 31 (pp. 179-185). London: SAGE.

Moreno, J.L. (1993). Who shall survive. ASGPP.

Sternberg, P., \& Garcia, A. (2000). Sociodrama: who's in your shoes. USA: Praeger.

Wiener, R. (2011). Notes from a European workshop: a protagonist-centred sociodrama. In Sociodrama in a changing world (pp. 29-31). www.lulu.com.

Wiener, R., Adderley, D., \& Kirk, K. (Eds.). (2011). Sociodrama in a changing world. www.lulu.com also available as hard copy or digital on Amazon. Accessed 1/6/21

\section{Further Reading}

iSCAN (International Sociodrama and Creative Action Network) iSCAN (International Sociodrama and Creative Action Network) website. www.sociodrama.co.uk. Accessed 1/6/21

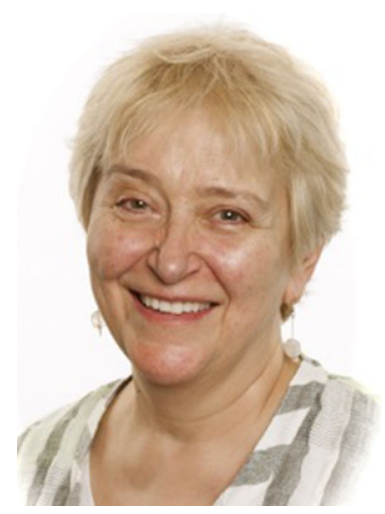

Diane Adderley is a Senior Trainer in Sociodrama and a Psychodrama Practitioner registered with the UK Council for Psychotherapy and accredited by the British Psychodrama Association. Diane was the first graduate of the MPV/SAM (Multi-Purpose Vehicle Sociodrama and Action Methods) diploma course in the UK, going on to be co-director of the school with founder Ron Wiener from 2006-2012. She is in private psychotherapy and coaching practice, runs groups online for iSCAN and is also an Accredited Playback Theatre Trainer. Her first career was as an actor and musician for over twenty years. 